\title{
Thoracoscopic Esophageal Atresia Repair First Ever Pakistanian Study, Early Learning Curve
}

\author{
Ali Raza Brohi ${ }^{1 *}$, Naseem Mengal ${ }^{2}$ and Rafia Tabassum ${ }^{3}$ \\ Peoples University of medical \& health sciences Nawabshah Sind Pakistan \\ Submission: October 27, 2016; Published: January 24, 2017 \\ *Corresponding author: Ali Raza Brohi, Professor \& Chairman Paediatric Surgery, Peoples University Of Medical \& Health Sciences, Nawabshah \\ Sind Pakistan, Tel: +923003209000; Email: Kidssurgeon@gmail.com
}

Keywords: Atresia; Esophagus; Thoracoscopic repair

\section{Introduction}

Esophageal atresia with or without fistula is rare congenital anomaly occurring in $1 / 3000-5000$ of neonatal population [1] which is traditionally repaired by posteriolateral thoracotomy\& still a standard approach, but this approach is associated with musculoskeletal morbidity and later in life scoliosis, chest wall deformity \& nerve damage [2-4]. With the advancement in minimal invasive paediatric procedures \& high definition technology and looking into consideration of these morbidities it become possible to perform technically demanding \& complex procedures thoracoscopicaly. In relation to this first time in 1999 isolated esophageal atresia done in male infant of 2 month which was repaired thoracoscopicaly [5]

For last 10 years after first repair refinement's in technique $\&$ feasibility in thoracoscopic repair of esophageal atresia led to adoption of this technique in many institutions world wide [1]

The objective of study is to do esophageal atresia thoracoscopicaly going through few basic steps of learning curve to make it possible for achievement of final thoracoscopic repair.

\section{Material and Methods}

This is retrospective study conducted from June 2015 to May 2016 at Peoples University of medical \& health sciences Nawabshah Sind, Pakistan \& 11 patients included for thoracoscopic esophageal atresia repair. Detailed pre-operative assessment done in all patients, fullterm with type $\mathrm{C}$ esophageal atresia weighing greater than $1.5 \mathrm{~kg}$ was selected. Neonates with major cardiac anomalies on echocardiography \& having GI anomalies were excluded. Preoperative assessment of gap between two atretic ends were roughly assessed by plain x-ray of cervical \& thoracic spine in lateral view with large bore tube in situ in esophagus.The distance between tube \& expected carina level at T4 measured and if it is more than two vertebrae expected to be larger gap between two ends (Figure 1) Data collected included newborn age \& weight at the time of surgery, operative time, mechanical ventilation required, days of hospitalization, time to start first feed $\&$ post-op complications.

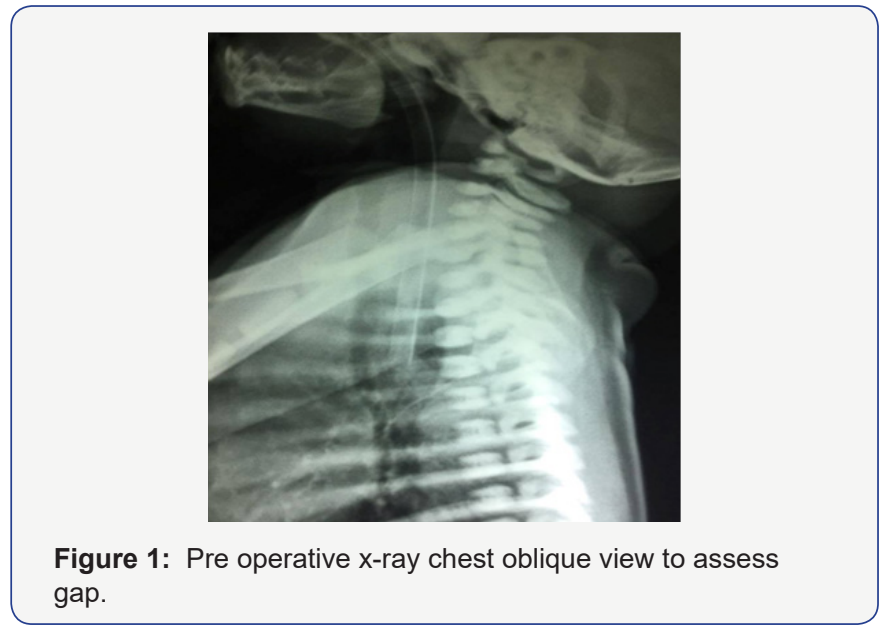

\section{Technique}

Baby placed in modified prone position with right side elevated at 45 degree with tracheal intubation in all cases \& no attempt was done for single lung ventilation. In first four cases single small incision of 2-3 cm like we do in VATS given below the tip of scapula at $5^{\text {th }}$ intercostal space. $5 \mathrm{~mm}$ scope put from top of incision \& two working $3 \mathrm{~mm}$ instruments places directly from mid of incision, lung retraction done with $3 \mathrm{~mm}$ fan retractor from bottom of incision .The aim of this technique was to see videoscopic view of internal anatomy and to assess difficulties while doing few of steps video-asisted like azygos vein ligation \& fistula dealing. Rest of procedure completed by open method. In next 7 cases three 
port technique was used consisted of camera port of $5 \mathrm{~mm}$ just below tip of scapula, right port of $5 \mathrm{~mm}$ in mid axillary line two space above camera port and the last $3 \mathrm{~mm}$ port placed two space below in $6^{\text {th }}$ or $7^{\text {th }}$ intercostal space behind posterior axillary line (Figure 2).
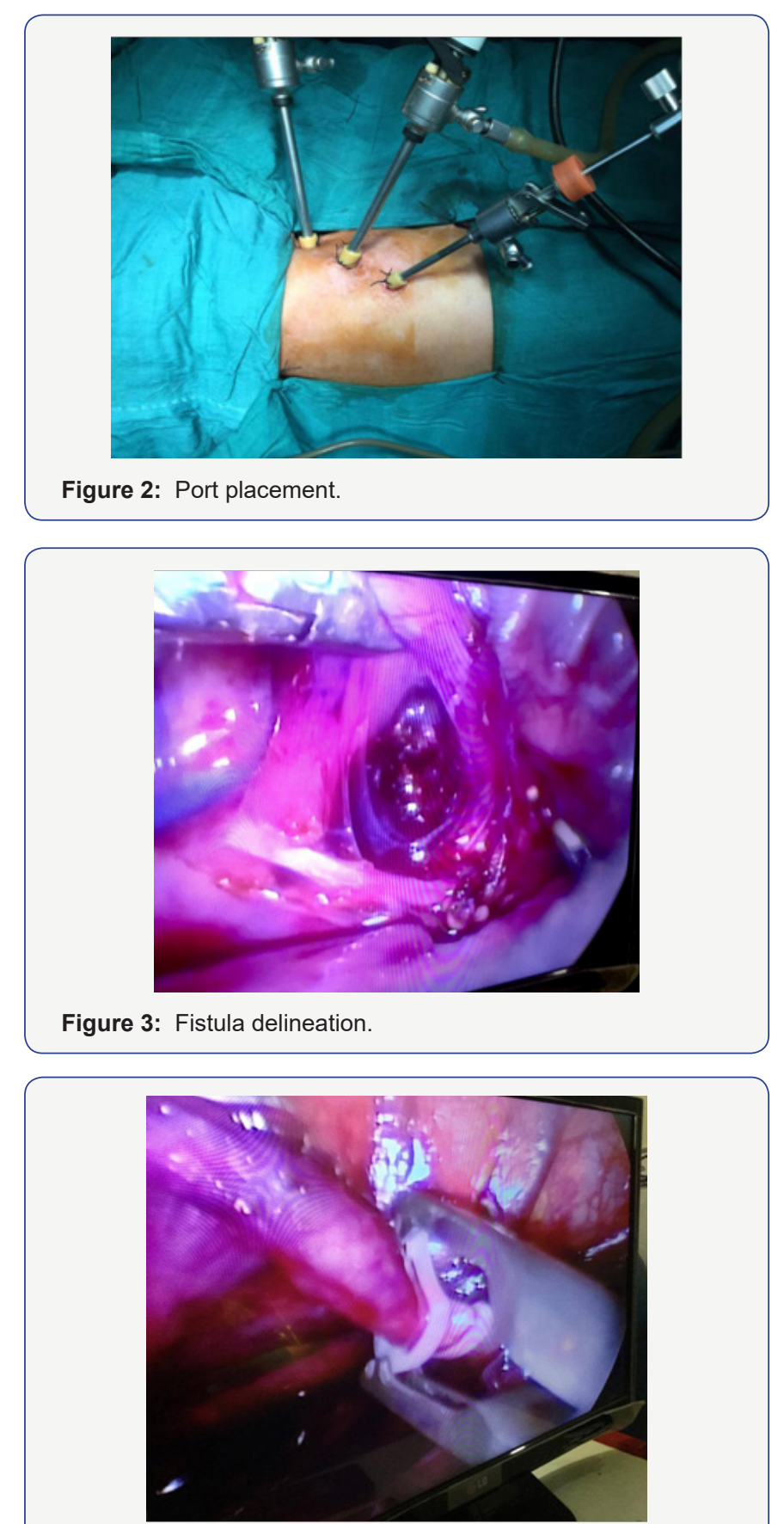

Figure 4: Fistula ligation with clip.

Lung collapse was done with Co2 insufflations with flow of 1lit/min \& pressure kept between 5-8 mmhg. The first step in all cases was to deal azygos, which was accomplished by hook electrode easily after opening the pleural membrane. Next step was to ligate with fistula (Figure 3) which was done with $5 \mathrm{~mm}$ of Grena plastic clips passed through right upper port (Figure 4)
Next was to identity the upper pouch, which was mobilized by hook in right hand and grasper in left hand to pull pouch inferiorly to achieve adequate length (Figure 5) Once the good length is achieved posterior layer of two ends was done intracorporeal by $5 / 0$ non-absorable in 2 cases and vicryl in rest of cases. After completing posterior layer trans anastomotic tube placed \& anterior layer of esophagus repaired (Figure 6) Chest drain placed in all cases.
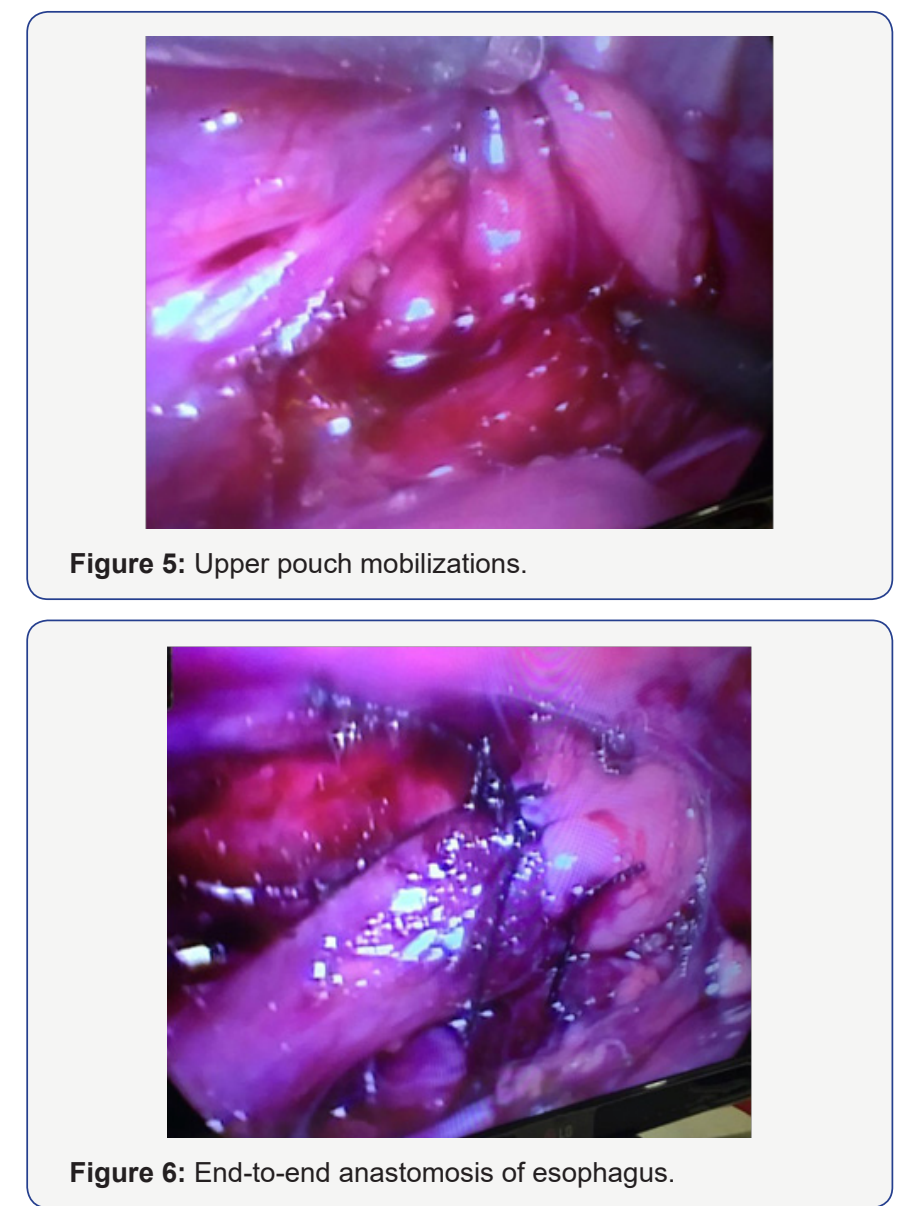

\section{Results}

Initial 4 cases out of 11 cases underwent video assisted like Uniportal VATS, which were later on converted to complete the procedure \&7 cases, were successfully done thoracoscopicaly. Mean age at the time of surgery was 3 days because most of patients coming late in our hospital \& mostly they are diagnosed postnatally. Weight of patients at the time of surgery ranges between $1.5-3.5 \mathrm{~kg}$ in the initial case as including the video assisted cases the operative time was bit longer between 120 to 150 minutes, which later on improved in last two cases was under 120 minutes. Mechanical ventilation required in 4 cases \&rest of patients were fine post operatively and only required oxygen support for few days.

Contrast swallow done in all case on day 5 but in 2 cases early contrast was done suspecting leak out of which one case had a confirmed leak, which was healed conservatively. First feed was 
started on day 3 in 4 cases through nasogastric tube which were clinically fine, in 5 cases feed started on day 5 after contrast swallow \& remaining two case feed started lately after 6 days as these were on mechanical ventilation.

Postoperative complications encountered in 3 cases out of which one had leak, one had stricture \& last one had reflux. Leak was managed conservatively, stricture improved on dilatation $\&$ gastro esophageal reflux managed on medical therapy. Days of hospitalization were variable ranging from 8 days to 16 days. There was one mortality in our series that patient presented late after 7 days \& died because of sepsis.

\section{Discussion}

According to IPEG \& EUPSA survey thoracoscopic esophageal repair is a world wide accepted procedure in more than 65 developed centers that are attempting but many aspects of EA management are lacking consensus they recommend establishment of an EA registry at the end of survey [6,7] .

In few Asian countries \& Middle East thoracoscopic repair of esophageal atresia has been started but they are at initial learning stage \& they have found same results as develop centers [8-10]. In Pakistan it is first ever study done which is going to be reported in order to follow the develop centers doing advance paediatric minimal invasive surgery. Details regarding advantage of thoracoscopic repair have been extensively studied like superior visualization, Cosmesis, identification of fistula \& avoidance of musculoskeletal morbidities $[1,11]$. In our study in the initial four cases we have adopted new technique like Uniportal VATS to learn the videoscopic anatomy \& to do procedure keeping the safety of patient in mind. Regarding age, weight \& associated anomalies our selection criteria was safe as we have excluded cases with low birth weight, prematurity \& major cardiac association are absolute contraindication to thoracoscopic approach as Rothenberg et al also described in his studies [12].

Azygos vein ligation or sparing is an option, which in our study in all case dealt with coagulating hook, but in few studies azygos sparing technique have been done claiming lesser edema at esophageal anastomotic site \& prevention of recurrent fistula formation $[8,9,13]$. Fistula ligation can be done in different ways like suture ligation, titanium clips but we have done with Grena $5 \mathrm{~mm}$ plastic clips which is having secure locking mechanism in front but there is no statistical significant difference in all techniques $[1,11,14]$.

The most difficult part of surgery is esophageal anastomosis intracorporeally which is technically demanding, the technique is same like open but the first stich is difficult one to apply because of apart ends, we have the same feelings especially in long gap where we have applied stays before applying first intracorporeal stich $[8,11]$. The operative time is variable in our study which was more in initial cases because of technical difficulty \& small working space, the same duration of operative time was seen in other studies with their initial learning curve experiences.
Although the number of patients in our series is small we cannot conclude issues related to post operative complication like leak \& anastomotic narrowing in our cases was only $10 \%$ each but different comparative studies have found these complication are lesser in thoracoscopy group versus open group $[15,16]$.

Recently study by borruto et al with Meta analysis shows no difference in open \& thoracoscopic group but the only advantage is to prevent major thoracotomy [17].

\section{Conclusion}

Thoracoscopic repair of esophageal atresia with TEF is feasible, but is technically challenging\& demanding.Our current experience is on quite limited number of patients and there is considerable learning curve required till the perfection of procedure. There is need to make refinements in the steps of the complex paediatric laparoscopic procedures to make it easy for surgeons wanting to adopt this procedure. Take home message is that a multi center program should be started in our part of world that should be guided by experienced surgeons from developed centers\& secondly advance suturing skills should be learned before starting this procedure.Avoidance of thoracotomy is a major advantage and is proven benefit in the recovery of patient.

\section{References}

1. Rothenberg SS (2012) Thoracoscopic repair of esophageal atresia \& tracheoesophageal fistula in neonate, Evolution of technique. J Laparoendosc Adv Surg Tech A 22(2): 195-199.

2. Freeman NV, Walkden J (1969) Previously unreported shoulder deformity following right lateral thoracotomy for esophageal atresia. J Paediatric Surg 4(6): 627-636.

3. Durning RP, Scoles PV, Fox OD (1980) Scoliosis after thoracotomy in tracheoesophageal fistula patient. A follow-up study. J Bone Joint Surg Am 62(7): 1156-1159.

4. Cherup LL, Siewels RD, Futerll JW (1986) Breast and pectoral muscle maldevelopment after anterolateral and posterolateral thoracotomies in children. Ann thorac surg 41(5): 492-497.

5. Lobe TE, Rothenberg SS, Waldschmidt J, Stroedter L (1999) Thoracoscopic repair of esophageal atresia in an infant: A surgical first. Pediatric Endosurgery \& Innovative Techniques 3(3): 141-148.

6. Augusto Z, Simon E, Micheal E, Puri P, Tovar J, et al. (2014) International survey on the management of esophageal atresia. Eur J Pediatr Surg 24(1): 3-8.

7. Lal D, Miano G, Juang D, Sharp NE, St Peter SD (2013) Current patterns of practice and technique in the repair of esophageal atresia and tracheoesophageal fistua: an IPEG survey. J Laparoendosc Adv Surg Tech A 23(7): 635-638.

8. Yamoto M, Urusihara N, Fukumoto K, Miyano G, Nouso H, et al. (2014) Thoracoscopic versus open repair of esophageal atresia with tracheoesophageal fistula at a single institution. Pediatr Surg Int 30(9): 883-887.

9. Kanojia RP, Bhardwaj N, Dwivedi D, Kumar R, Joshi S, et al. (2016) Thoracoscopic repair of esophageal atresia with tracheoesophageal fistula: Basics of technique and its nuances. J Indian Assoc Pediatr Surg 21(3): 120-124.

10. Hassan ME, Khalid Al Ali (2014) First thoracoscopic repair of tracheoesophageal fistula in UAE: a case report \& review of literature. Ann of paediatr surg 10(2): 46-49. 
11. Rothenberg SS (2014) Thoracoscopic repair of esophageal atresia \& tracheoesophageal fistula in neonates the current state of art. Paediatr surg int 30(10): 979-985.

12. Rothenberg SS (2005) Thoracoscopic repair of esophageal atresia\& tracheoesophageal fistula. Semin pediatr surg 14(1): 2-7.

13. Vander Zee DC, Bax KN (2007) Thoracoscopic treatment of esophageal atresia with distal fistula \& of Tracheomalacia. Semin pediatric surg 16(4): 224-230

14. Holcomb GW, Rothenberg SS, Bax KM, Martinez-Ferro M, Albanese CT, et al. (2005) Thoracoscopic repair of esophageal atresia \& tracheoesophageal fistula, a multi institutional analysis. Ann surg 242(3): 422-428.

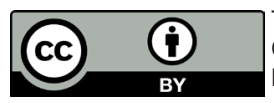

This work is licensed under Creative Commons Attribution 4.0 Licens

DOI: 10.19080/AJPN.2017.02.555593
15. Lugo B, Malhotra A, Gunner Y (2008) Thoracoscopic versus open repair of esophageal atresia \& tracheoesophageal fistula. J laproendosc adv. surg tech 18(5): 753-756.

16. AL Tokhais T, Zamakhasharay M, Aldekhail S, Mandora H, Sayed S, et al. (2008) Thoracoscopic repair of tracheoesophageal fistula; a case control mathed study. Jpediatric surg 43(5): 805-809.

17. Borrutu F, Impilizzeri P, Monatatto A, Antonuccio P, Santacaterina E, et al. (2012) Thoracoscopic versus thoracotomy for esophageal atresia with tracheoesophageal fistula: review of literature \& meta analysis. Eur j pediatr surg 22(6): 415-419.

\section{Your next submission with Juniper Publishers will reach you the below assets}

- Quality Editorial service

- Swift Peer Review

- Reprints availability

- E-prints Service

- Manuscript Podcast for convenient understanding

- Global attainment for your research

- Manuscript accessibility in different formats

( Pdf, E-pub, Full Text, Audio)

- Unceasing customer service

Track the below URL for one-step submission

https://juniperpublishers.com/online-submission.php 